\title{
Study on the promotion of STEM literacy education students majoring in preschool
}

\author{
YAN Mei \\ RIZHAO POLYTECHNIC, Rizhao City, Shandong 276826, China
}

Keywords: preschool education; STEM literacy; training strategy

\begin{abstract}
STEM education as a hot topic in recent years in the field of education K 12. More and more countries attach importance to it. The United States issued 2013 "a new generation of science education standards" will be formally introduced, engineering science education, from kindergarten to high school continues to directly indicate the necessity of STEM education, STEM education preschool stage is becoming a hot topic, at the same time, how to cultivate students of preschool education major STEM literacy, also has become a common concern of the current education the topic of. Based on this, this is what, why and how to discuss the idea of preschool education students STEM literacy training problems, put forward related education strategies, in order to lay a solid foundation for the healthy development of preschool education students.
\end{abstract}

\section{Introduction}

The twenty-first Century has entered the era of knowledge economy, the competition of globalization is the competition between science and technology and talent, and the United States puts forward the science, technology, engineering and mathematics education in the field of education, that is, STEM education. STEM is made up of the first letter of English words in four disciplines, Science (Science), technology (Technology), engineering (Engineer) and Mathematics (Mathematics). STEM education is the reflection of STEM concept in education, and it is a reflection on putting educational practice into practice. STEM was proposed by the National Science Foundation in 2001 in its educational programs, and then the United States mentioned STEM in a variety of policies and bills. In the state of the Union address in 2006, President Barack Obama proposed cultivating people with STEM literacy. The government of the United States STEM education high attention, increasing attention and commitment to STEM education, make it become the focus of the current basic education reform in america. At the same time, all countries in the world are actively promoting the development of STEM education.

\section{STEM literacy overview}

In recent years, with the development of STEM education in primary and secondary schools, American preschool education is also paying close attention to STEM education. At the 2015 American Preschool Education Conference (NAEYC), STEM became a hot topic, which was reported by many sub venues, and dozens of related papers were exchanged at the annual meeting. STEM education is a new educational concept, how to cultivate the students' attention to real life, to guide them to try to solve practical problems in life, we need teachers with "STEM literacy", re-examine the education mode has the usual usually with STEM thinking.

The Nobel prize winning founder Leon Lederman, Illinois, math and Science Research Institute (LeonLederman) defined as STEM literacy; in the era of knowledge economy, STEM literacy is the ability to adapt and accept new technology products to bring change, is multi-faceted influence predict their actions, the complex ideas for. Method to find unknown human creative problem solving to. STEM literacy refers to the ability of individuals to apply their own understanding of the world to four interrelated domains. STEM this interdisciplinary discipline will be originally scattered four 
disciplines set into a whole, these four disciplines represent four categories of literacy. STEM education focuses on the cultivation of these four qualities of students.

First, scientific literacy (Scientific literacy), is the use of scientific knowledge and process (such as physics, chemistry, biological science and understanding of the nature of earth and Space Sciences), and ability in making decision about the nature of the influence. Includes three fields: the life and Health Sciences, earth and Environmental Sciences, science and technology.

Second technical literacy (Technological literacy), that is, the ability to use, manage, understand and evaluate technology in the world today. In the use of technology, students should correct operation of key products and systems, understand the macro system existing and human adaptive system composition and operation; in the management of technology, students should ensure the effectiveness and appropriateness of all technical activities; in the understanding of the technology, not only need to know the facts and information, but also need to have the information is comprehensive, the formation of new ideas for; in the evaluation of technology, students should be able to according to the facts rather than emotion, make a fair judgment and decision of technology.

Third, engineering literacy (Engineering literacy), that is, the ability to understand the engineering design and opening process. Engineering course is a project based curriculum, which integrates the knowledge of many subjects, makes the difficult concepts to be closely related to students' real life, and can stimulate students' interest in solving problems.

Fourth, Mathematical literacy refers to students' ability to analyze, infer and communicate effectively when they discover, express, solve and explain mathematical problems in a variety of situations.

STEM literacy is not a simple combination of scientific literacy, technical literacy, engineering literacy and mathematical literacy. STEM curriculum is the process of changing the knowledge and process of each subject learned by students into a process of exploring the different sides of the world. The feature of STEM classroom is to emphasize students' ability to design and solve problems in the "disordered" learning environment.

In September 18, 2017, research center of STEM education Chinese Education Scientific Research Institute organized the "STEM grade standard of teachers' ability (Draft)" (hereinafter referred to as the "standard") experts, the "standard" is divided into seven level indicators, respectively. STEM value of education understanding, science and Applied Mathematics, engineering and technology in practice, interdisciplinary understanding and practice, STEM curriculum development and integration, implementation and evaluation, STEM STEM teaching environment creation and use, the first four index is on Teachers' internal to the multidisciplinary and interdisciplinary aspects of personal endowments and literacy evaluation index (including cognition, understanding, knowledge, skills and other aspects). After the three index is related to aspects of the implementation of STEM education for teachers (curriculum development, evaluation tools, environment evaluation index). The former is the process of internalization, and the latter is externalization. The "standard" fully embodies the unity of knowledge, STEM teachers have both ability and political integrity inside and outside quality requirements.

\section{Why should improve preschool education students literacy STEM}

September 2016. "Early STEM education" is one of the 8 challenges of STEM education innovation in the STEM2026:STEM Educational Innovation vision jointly issued by the American Research Institute and the United States Department of education. How to study and implement STEM education in kindergarten stage will undoubtedly become the next research hotspot. Preschool education students are the future preschool teachers, and improving the STEM literacy of preschool education students can undoubtedly promote STEM education in kindergartens. 
(1) It is conducive to further expand the theory of teacher education, giving preschool teachers professional development of new connotations.

Practice of promoting STEM education reform and development of preschool education majors in college, especially for their use of special training strategies and training mode, to adapt to the situation of preschool teachers' training mode, a bold attempt to comprehensive, interdisciplinary, from single subject teachers' independent culture transition to the comprehensive training of several related courses for teachers. This broadens the Horizons Preschool Teacher Education Research, expand teacher education theory, the theory of teacher professional development with new connotation, significance.

\section{(2) It is helpful to strengthen the training of preschool teachers and optimize the structure of teachers.}

The development of science and technology education in our country attaches great importance to science and technology, emphasize the subject status, focusing on engineering status only however in the higher education stage, in kindergarten and elementary education stage, our concern is still science and mathematics of these two basic subjects, technology at the edge, as for the project, almost hard to find and in schools, there is no engineering teachers there. The United States emphasizes STEM education, but the engineering education is particularly weak. Therefore, in order to ensure the balanced development of the four disciplines, the United States has made great efforts to train engineering teachers to promote the development of Engineering education. The United States in these areas has been relatively mature, the curriculum reform of our country, strengthen the math and Science College preschool teachers, especially the whole optimization of teacher training, engineering and technology course teaching, has important significance.

\section{(3) It is helpful to grasp the development trend of international education reform and gain useful reform experience.}

Study on college students of preschool education major STEM attainment problem can deepen our understanding of STEM education reform, to further understand and grasp the trend of education reform and development in developed countries, their reforms as a mirror, a reflection on China's education reform and development, understand the current reality of education, so as to better formulate and adjust, the evaluation of education reform and development policy of our country, deepening the reform and development of education practice. The United States for action and measures to cultivate STEM teachers, such as the training of STEM teachers to rise to the height of the legislative, teacher education programs to provide continuing support and establish accountability mechanisms, the development of alternative approaches to teacher certification, teacher education reform, the establishment of educational supervision and evaluation mechanism, ways of training the innovative teachers of our system, expand the source of teachers, have important reference value to improve the quality of teachers. In addition, the main body of the action is well coordinated, shoulder the responsibility of STEM teacher training, reflecting the high degree of flexibility and unity, which is also worth learning.

\section{Improve preschool education students STEM Literacy Strategy}

\section{(a) The development of the STEM education, strengthen the training of teachers pressure STEM}

First, our country should be in line with international standards, strengthen STEM education preschool education professional students, improve the quality of university teachers, cultivate innovative talents, for future power, especially to the introduction of engineering education, focus on the cultivation of engineering teachers, from the overall optimization of teachers. Science, 
technology, engineering and mathematics related to national innovation and global competitiveness, the superpower will into the field of preschool education. In China, how can only in the higher education stage is to cultivate engineering talents? China is committed to the training of engineering teachers should carry out teacher education programs, while training new teachers in teaching engineering, while professional training in mathematics, science, information technology and other subject teachers, so that they gradually understand contact engineering, engineering, engineering with the more familiar, trying to design engineering courses, Professor of Engineering the course, the students before entering the University, have more understanding of the project, reduce the professional selection of confusion. Teachers can also use the advanced information technology, online learning, professional learning whenever and wherever possible material from the network, obtain continuous support, thus changing the current stage of Engineering Education in primary and secondary schools and kindergartens lack this situation.

\section{(b) The way of cultivating innovative teachers, focusing on joint training force}

First of all, in the process of preschool teacher training in China, we should adopt the strategy of Cross School joint training of STEM teachers. UTeach projects such as the United States, with a cross school joint training mode to train the next generation of the STEM teachers, the existing gap between the college and the elimination of preschool education of mathematics, science, engineering, build a bridge between preschool education and mathematics, science, technology, engineering professional. Second, our country in preschool teachers training, should strengthen cooperation with the kindergarten, as soon as possible for students to promote their teaching practice, to better integrate into the classroom, to better adapt to the occupation of preschool teachers, should try to began to arrange the teaching practice from the first year of observation, let students enter the classroom, back step by step is solely responsible for a class. They are learning at the same time, all the way to explore the teaching practice, theory and practice in the process of continuous collision, mutual penetration of the essence of education also understand more thoroughly, the course of study and teaching practice for a step, let the teaching practice throughout the University career. Finally, our country should promote the typical and successful teacher training mode, encourage colleges and universities to adopt this mode, train teachers with cooperation, and produce scale effect. Moreover, in the process of cooperative training to strengthen communication, the future of what kind of teacher training should have more imagination and consensus, not a school, a college alone.

\section{(c) The establishment of national excellent preschool education professional teachers' professional learning community, professional sharing}

Our country should establish a national excellent preschool education professional teachers' professional learning community. The goal is to create a high quality professional team of teachers with noble morality, excellent service, reasonable structure and full of vigor, and train a batch of famous teachers and leading scholars. Then, China can learn from the United States STEM excellent teacher team construction initiatives. In a nationwide selection of a number of top teachers, set up a certain duration and high compensation, expiration is required to participate in the selection, so that these discipline leader has a sense of crisis, continuous self-improvement, and inspire other ordinary teachers to become the new leader of the spirit of discipline. But these are not the selection between excellent teachers mutually isolated, not only as a regional leader and independent discipline activities, but with other selected teachers around the country to form a professional learning community, face-to-face or frequent exchanges and interaction through the network, out of the school in this area, the city of the province, or the circle, to confront the situation education nationwide. After that, these teachers act as teachers, teachers, teachers and representatives of leading role, will share the domestic advanced concepts, effective teaching mode to the local ordinary teachers, promote the professional development of the teachers. Of course, the original of this school, the District, the city or the province of professional learning community based on the needs and to show up as in the past, and to strengthen the connection between the professional learning community. 


\section{(d) Strengthen the government's internal coordination, mobilize social forces to participate in the preschool education professional teacher education activities}

First, China should strengthen the cooperation and cooperation among government departments to ensure the continuous development of preschool teachers' professional training and professional development activities. The training of teachers and their professional development is not only rely on the strength and the Ministry of Finance and the Ministry of education funding, but should be combined with each of the relevant departments jointly committed to qualified, high quality, and excellent teacher training. Second, our country should actively encourage and fully mobilize all the forces to assist the development of teachers and professional development activities. In addition to federal and state governments, universities, schools and other actors, private organizations, non-profit organizations, professional associations and other social forces also participated in the training of teachers in STEM, or provide financial support, or provide material, equipment, infrastructure support, or provide teacher support or informal learning opportunities, good cooperation between the various actors, to bear the heavy responsibility of STEM teacher training. China can learn from this way, not only the school and the administrative department of education to do everything, all activities, fees only from the educational expenditure allocation, carry out the project site, equipment, personnel and funds, enterprises can also use the fund organization. We should make good use of the advantages of other organizations in the society, fully rely on their strength, mobilize all possible resources, and ensure the efficient, orderly, smooth and sustainable development of teachers' training and professional development.

Innovative talent is the core competitiveness of the country's development, is the key countries in the global competition, especially closely related with innovation in science, technology, engineering and math talent training is the key in the key. Therefore, the United States to develop STEM education, established the strategic priority of STEM education, especially to pragmatic preschool education and basic education stage of STEM education, and the most critical part is the STEM teacher. In order to improve preschool education should strengthen the cultivation of pre service, but also pay attention to the professional development of teachers, we must follow the road of traditional culture, but also another kick size, expansion of teaching sources, it is necessary to improve access standards for teachers, teacher training and construction of accountability mechanisms, both government forces, but also to mobilize social resources, pay attention to multi agent collaborative cooperation, in order to achieve results. In particular, need to further strengthen the training of engineering teachers, make up the short board, to promote the balanced development of STEM education, improve the overall quality of STEM education, we should actively with the international standards, try to introduce engineering education in preschool education and basic education, and lay a solid foundation for the innovative talents cultivation of higher education stage. Actively innovative teacher training mode, the Cross School joint training way, strengthen the cooperation between university teachers training, improve the teachers' education level, at the same time open up alternative teacher certification path, attract outstanding talents to enter the STEM Library of teachers. To strengthen the professional development of teachers, establish a national professional learning community, strengthen teachers nationwide connection, mobilize all social forces to participate in and support training and professional development of teachers, and strengthen the supervision of teacher education institutions, to confirm its qualification, quality and training guarantee of teachers.

\section{Acknowledgements}

Fund Project: Science and technology plan project of Shandong colleges and Universities 2017. Name: Study on the cultivation of college students majoring in preschool education professional ability from the perspective of STEM Education. Item number: J17RA157. 


\section{References}

[1] Yang Guangfu. The Obama administration STEM education reform review J. Management of primary and secondary schools, 2014

[2] Ding Jie, Cai Su, Jiang Yu. Fengguang, educational science and technology, engineering and mathematics innovative education and interdisciplinary research from the second STEM International Conference on education of J. Open education research Qiao, 2013 (2) pressure.

[3] Huang Xiao, Li Yang. On the characteristics of STEM Education [J]. Jiangsu education research.2014.

[4] Zhao Zhongjian.STEM: American education strategy of "in J. Shanghai education, 2012 pressure

[5] Dong Zehua. The development of American STEM education to deepen the development of science and education in China [J]. education guide.2015 